\title{
Review of Monte Carlo All-Particle Transport Codes and Overview of Recent MCNPX Features
}

\section{G. McKinney*}

Los Alamos National Laboratory

P.O. Box 1663, MS K575, Los Alamos, NM, USA

E-mail: gwm@lanl.gov

\section{J. Durkee, J. Hendricks, M. James, D. Pelowitz, and L. Waters}

Los Alamos National Laboratory

P.O. Box 1663, MS K575, Los Alamos, NM, USA

E-mail: jdurkee@lanl.gov, jxh@lanl.gov, mrjames@lanl.gov, dbp@lanl.gov, lsw@lanl.gov

\begin{abstract}
Several Monte Carlo all-particle transport codes are under active development around the world. A high-level capability review of these transport codes is provided. Furthermore, an overview of recent features that are of interest to fast neutron detection and applications is given for one of these codes, namely MCNPX. MCNPX is the Monte Carlo N-Particle eXtended version of MCNP4C that has been under continuous development for more than a decade. In addition to all of the MCNP4C capabilities, MCNPX can transport 34 different particle types up to the teravolt energy range. In this paper we focus on a subset of the twenty-eight new features developed since the release of MCNPX 2.4.0 and included in the release of 2.5.0.
\end{abstract}

International Workshop on Fast Neutron Detectors

University of Cape Town, South Africa

April 3 - 6, 2006

\footnotetext{
${ }^{*}$ Speaker
} 


\section{Review of monte carlo all-particle transport codes}

Several Monte Carlo all-particle transport codes are under active development around the world, including MCNPX [1], GEANT4 [2], FLUKA [3], MARS [4], and PHITS [5]. Each of these codes represents hundreds of man-years of development effort, hundreds of thousands of lines of code, and hundreds of pages of documentation. Furthermore, the means by which a user interacts with these codes is quite different, ranging from constrained input files to userdeveloped source code. Therefore, as one might expect, producing a succinct overview of code capabilities is not a trivial undertaking. Such an overview is perhaps best captured in a tabular format; however one must keep in mind that there are obvious limitations to such a comparative format, as elaborated below.

First, we'll discuss some of the ground rules applied to this comparison. Since all of these codes are developed using standard programming languages and their source files are somewhat readily available, it is clear that a code user can modify any of them to achieve whatever capability they may desire. Thus, to obtain credit for a feature or capability listed in the following tables, it was required that a specific input option be available to provide that capability or, alternatively, one or more enabling routines provided to accomplish an equivalent effect. It is important to note that for each of these codes, a lead developer was involved in substantiating that code's capabilities.

Next, it is important to discuss some of the limitations of our comparative format. The list of capabilities provided here is clearly not a superset accumulated across all these transport codes, rather it is a list of features deemed most important by these authors and the various lead developers. Furthermore, most of these capabilities include implementation details which vary significantly across the various codes. Perhaps in future extensions to this work, such details will be illuminated. To achieve our goal of brevity, the reader should note our use of "*” to denote that a listed technique or algorithm has been extended or modified. In such cases, we refer the reader to the appropriate code documentation for additional clarification. Finally, for the MCNPX column, references to a code version (e.g., 2.5.C) indicate a capability that is currently under development, with the version mnemonic providing some indication of when that feature will be available.

Tables 1-6 provide an overview of information about and capabilities within the various Monte Carlo all-particle transport codes. 
Table 1. Overview of general information for various all-particle transport codes.

\begin{tabular}{|c|c|c|c|c|c|}
\hline General & MCNPX & GEANT4 & FLUKA & MARS & PHITS \\
\hline Version & 2.5 .0 & $8.0 \mathrm{p} 1$ & 2005 & 15 & 2.09 \\
\hline Lab. Affiliation & LANL & $\begin{array}{l}\text { CERN } \\
\text { IN2P3 } \\
\text { INFN } \\
\text { KEK } \\
\text { SLAC } \\
\text { TRIUMF } \\
\text { ESA }\end{array}$ & $\begin{array}{l}\text { CERN } \\
\text { INFN }\end{array}$ & FNAL & \begin{tabular}{|l|} 
JAEA \\
RIST \\
GSI \\
Chalmers Univ.
\end{tabular} \\
\hline Language & Fortran $90 / \mathrm{C}$ & $\mathrm{C}++$ & Fortran 77 & Fortran 95/C & Fortran 77 \\
\hline Cost & Free & Free & Free & Free & Free \\
\hline \begin{tabular}{|l|} 
Release Format \\
\end{tabular} & Source \& binary & Source \& binary & Source \& binary & Binary & Source \& binary \\
\hline User Manual & 470 pages & 280 pages & 387 pages & 150 pages & 176 pages \\
\hline Users & 2000 & $\sim 2000$ & $\sim 1000$ & 220 & 220 \\
\hline Web Site & mcnpx.lanl.gov & cern.ch/geant4 & www.fluka.org & $\begin{array}{l}\text { www-ap.fnal. } \\
\text { gov/MARS }\end{array}$ & Under const. \\
\hline Workshops & 7/year & 4/year & $\sim 1 /$ year & $\sim 2 /$ year & $\sim 1 /$ year \\
\hline \begin{tabular}{|l|} 
Input Format \\
\end{tabular} & Free & $\begin{array}{l}\mathrm{C}++ \text { main } \\
\text { Fixed geometry }\end{array}$ & Fixed or free & Free & Free \\
\hline Input Cards & $\sim 120$ & N/A & $\sim 85$ & $\sim 100$ & $\sim 100$ \\
\hline Parallel Execution & Yes & Yes & Yes & Yes & Yes \\
\hline
\end{tabular}

Table 2. Overview of geometry capabilities for various all-particle transport codes.

\begin{tabular}{|c|c|c|c|c|c|}
\hline Geometry & MCNPX & GEANT4 & FLUKA & MARS & PHITS \\
\hline Description & MCNP-based & $\begin{array}{l}\text { STEP Solids } \\
\text { (Boolean CSG) }\end{array}$ & $\overline{\text { MORSE-based }}$ & $\begin{array}{l}\text { Solids } \\
\text { MCNP-based } \\
\text { User defined }\end{array}$ & $\begin{array}{l}\text { MCNP-based } \\
\text { MORSE-based }\end{array}$ \\
\hline \begin{tabular}{|l} 
Extensions \\
Twisted \\
Nested \\
Repeated \\
Voxel
\end{tabular} & $\begin{array}{l}\text { No } \\
\text { Yes (universes) } \\
\text { Yes } \\
\text { Lattice (rec, hex) }\end{array}$ & $\begin{array}{l}\text { Yes } \\
\text { Yes (logical vol.) } \\
\text { Yes } \\
\text { Yes (rec, cyl) }\end{array}$ & $\begin{array}{l}\text { No } \\
\text { No } \\
\text { Yes } \\
\text { Yes }\end{array}$ & $\begin{array}{l}\text { No } \\
\text { Yes } \\
\text { Yes } \\
\text { Yes }\end{array}$ & $\begin{array}{l}\text { No } \\
\text { Yes (universes) } \\
\text { Yes } \\
\text { Lattice (rec, hex) }\end{array}$ \\
\hline \begin{tabular}{|l} 
Reflections \\
\end{tabular} & 3 types & Yes & Yes & Yes & Neutron albedo \\
\hline $\begin{array}{l}\text { Viewer } \\
\text { Debugger }\end{array}$ & $\begin{array}{l}\text { Built-in: } \\
\text { 2-D Interactive } \\
\text { X-Windows } \\
\text { External: } \\
\text { Vised } \\
\text { Moritz }\end{array}$ & $\begin{array}{l}\text { Built-in: } \\
\text { 3-D Interactive } \\
\text { OpenGL } \\
\text { OpenInventor } \\
\text { RayTracer } \\
\text { External: } \\
\text { WIRED } \\
\text { VRML } \\
\text { DAWN }\end{array}$ & $\begin{array}{l}\text { Built-in: } \\
\text { None } \\
\text { External: } \\
\text { Custom (X11) }\end{array}$ & $\begin{array}{l}\text { Built-in: } \\
\text { 2-D Interactive } \\
\text { Tcl/Tl } \\
\text { 3-D Interactive } \\
\text { OpenGL } \\
\text { External: } \\
\text { Custom }\end{array}$ & $\begin{array}{l}\text { Built-in: } \\
\text { 2,3-D Command } \\
\text { PS via Angel } \\
\text { External: } \\
\text { Angel } \\
\text { PS }\end{array}$ \\
\hline Setup GUI & $\begin{array}{l}\text { Vised } \\
\text { Moritz }\end{array}$ & GGE & No & $\mathrm{Tcl} / \mathrm{Tl}$ & No \\
\hline CAD & STEP via GUI & STEP & No & No & No \\
\hline Fields (E/B) & 2.6.D & Yes & Yes & Yes & Yes \\
\hline Moving & 2.6.D & Yes & Yes & No & Yes \\
\hline
\end{tabular}


Table 3. Overview of source capabilities for various all-particle transport codes.

\begin{tabular}{|l|l|l|l|l|l|}
\hline Source & \multicolumn{1}{|c|}{ MCNPX } & \multicolumn{1}{|c|}{ GEANT4 } & \multicolumn{1}{c|}{ FLUKA } & MARS & PHITS \\
\hline Fixed & & & & & \\
General & & & & \\
Explicit & Yes & Yes & Yes & Yes & Yes \\
Distribution & Yes & Yes & No & Yes & Yes \\
Dep. Dist. & Yes & GPS & No & Yes & Yes \\
External & SSW/SSR & Yes & No & Yes & Yes \\
User Sub. & Yes & Yes & Yes & Yes & Yes \\
\hline Eigenvalue & Yes & No & No & No & No \\
\hline Burnup & Yes (2.6.A) & No & No & No & No \\
\hline
\end{tabular}

Table 4. Overview of physics capabilities for various all-particle transport codes.

\begin{tabular}{|c|c|c|c|c|c|}
\hline Physics & MCNPX & GEANT4 & FLUKA & MARS & PHITS \\
\hline Particles & 34 & 68 & 68 & 41 & 38 \\
\hline $\begin{array}{l}\text { Charged particles } \\
\text { Energy loss } \\
\text { Scatter } \\
\text { Straggling } \\
\text { XTR/Cheren. }\end{array}$ & $\begin{array}{l}\text { CSDA } \\
\text { Bethe-Bloch } \\
\text { Rossi } \\
\text { Vavilov } \\
\text { No }\end{array}$ & $\begin{array}{l}\text { CSDA } \\
\text { Bethe-Bloch } \\
\text { Lewis } \\
\text { Urban } \\
\text { Yes }\end{array}$ & $\begin{array}{l}\text { CSDA } \\
\text { Bethe-Bloch } \\
\text { Moliere } \\
\text { Custom } \\
\text { No/yes }\end{array}$ & $\begin{array}{l}\text { CSDA } \\
\text { Bethe-Bloch } \\
\text { Moliere* } \\
\text { Custom } \\
\text { No }\end{array}$ & $\begin{array}{l}\text { CSDA } \\
\text { Bethe-Bloch } \\
\text { Moliere } \\
\text { Vavilov } \\
\text { No } \\
\end{array}$ \\
\hline $\begin{array}{c}\text { Baryons } \\
\text { Neutron } \\
\text { Low } \\
\text { High } \\
\text { Proton } \\
\text { Low } \\
\text { High } \\
\text { Other }\end{array}$ & $\begin{array}{l}\text { Cont. (ENDF) } \\
\text { Models } \\
\text { Cont. (ENDF) } \\
\text { Models } \\
\text { Model List: } \\
\text { Bertini } \\
\text { ISABEL } \\
\text { CEM } \\
\text { INCL } \\
\text { FLUKA } 89>3 \mathrm{GeV} \\
\text { LAQGSM }(2.6 . \mathrm{C}) \\
\end{array}$ & $\begin{array}{l}\text { Cont. (ENDF) } \\
\text { Models } \\
\text { Models } \\
\text { Models } \\
\text { Model list: } \\
\text { Hadron-nucleous } \\
\text { GHEISHA* } \\
\text { INUCL(Bertini) } \\
\text { BIC } \\
\text { CHIPS } \\
\text { QGS/FTF>8 GeV }\end{array}$ & $\begin{array}{l}\text { Multigroup(72) } \\
\text { Models } \\
\text { Models } \\
\text { Models } \\
\text { Model list: } \\
\text { PEANUT(GINC) } \\
\text { DPM+Glauber > } \\
5 \text { GeV }\end{array}$ & $\begin{array}{l}\text { Cont. (ENDF) } \\
\text { Models } \\
\text { Models } \\
\text { Models } \\
\text { Model list: } \\
\text { Custom } \\
\text { CEM } \\
\text { LAQGSM } \\
\text { DPMJET }\end{array}$ & $\begin{array}{l}\text { Cont. (ENDF) } \\
\text { Models } \\
\text { Models } \\
\text { Models } \\
\text { Model list: } \\
\text { Bertini } \\
\text { JAM }>3 \mathrm{GeV}\end{array}$ \\
\hline $\begin{array}{l}\text { Leptons } \\
\text { Electrons } \\
\text { Muon } \\
\text { Neutrino } \\
\text { Other } \\
\end{array}$ & $\begin{array}{l}\text { ITS } 3.0 \\
\text { CSDA/decay } \\
\text { Production } \\
\text { Decay }\end{array}$ & $\begin{array}{l}\text { EEDL, EADL } \\
\text { Models } \\
\text { Production } \\
\text { Decay }\end{array}$ & $\begin{array}{l}\text { Custom } \\
\text { Models } \\
\text { Models } \\
\text { Decay }\end{array}$ & $\begin{array}{l}\text { Custom } \\
\text { Models } \\
\text { Models } \\
\text { Models }\end{array}$ & $\begin{array}{l}\text { ITS } 3.0 \\
\text { CSDA/decay } \\
\text { Models } \\
\text { Models } \\
\end{array}$ \\
\hline Mesons & Models & Models & Models & Models & Models \\
\hline $\begin{array}{l}\text { Photons } \\
\text { Optical } \\
\text { x-ray/g } \\
\text { Photonuclear }\end{array}$ & $\begin{array}{l}\text { No } \\
\text { ITS } 3.0 \\
\text { Libraries (IAEA) } \\
\text { CEM }\end{array}$ & $\begin{array}{l}\text { Yes } \\
\text { EPDL97, EADL } \\
\text { CHIPS }\end{array}$ & $\begin{array}{l}\text { Yes } \\
\text { Custom+EPDL97 } \\
\text { PEANUT } \\
\text { VMDM }\end{array}$ & $\begin{array}{l}\text { No } \\
\text { Custom } \\
\text { Custom } \\
\text { CEM }\end{array}$ & $\begin{array}{l}\text { No } \\
\text { ITS } 3.0 \\
\text { No }\end{array}$ \\
\hline Ions & $\begin{array}{l}\text { ISABEL } \\
\text { LAQGSM (2.6.C) }\end{array}$ & $\begin{array}{l}\text { AAM } \\
\text { EDM } \\
\text { BLIC }\end{array}$ & $\begin{array}{l}\text { RQMD-2.4 } \\
\text { DPMJET-3 }\end{array}$ & LAQGSM & $\begin{array}{l}\text { JQMD } \\
\text { JAMQMD > } \\
3 \mathrm{GeV} / \mathrm{u}\end{array}$ \\
\hline Delayed & $\mathrm{n}, \gamma(2.6 . \mathrm{C})$ & $\alpha, \beta, \gamma$ & $\beta, \gamma$ & $\gamma$ & $n$ \\
\hline
\end{tabular}


Table 5. Overview of tally capabilities for various all-particle transport codes.

\begin{tabular}{|c|c|c|c|c|c|}
\hline Tallies & MCNPX & GEANT4 & FLUKA & MARS & PHITS \\
\hline \multicolumn{6}{|l|}{ Standard } \\
\hline \multicolumn{6}{|l|}{ Flux } \\
\hline Volume & Yes & Yes & Yes & Yes & Yes \\
\hline Surface & Yes & Limited & Yes & Yes & Yes \\
\hline Point/ring & Yes & No & No & Yes (neutrons) & No \\
\hline Current & Yes & Limited & Yes & Yes & Yes \\
\hline Charge & Yes & Yes & Yes & Yes & Yes \\
\hline Kinetic energy & Yes & Yes & Yes & Yes & Yes \\
\hline Particle density & Yes & Yes & No & No & No \\
\hline Reaction rates & Yes & No & Star (inelastic) & Yes & Yes \\
\hline Energy deposition & Yes & Yes & Yes & Yes & Yes \\
\hline Rapidity & No & Yes & Yes & Yes. & No \\
\hline DPA & HTAPE3X & $? ?$ & Some & Yes & Yes \\
\hline Momentum & No & Yes & Yes & Yes & No \\
\hline Pulse-height & Yes & User input & Yes & No & Yes \\
\hline Termination & Partial & $? ?$ & Yes & Partial & Yes \\
\hline Modifiers & 9 & 2 & 2 & 2 & 2 \\
\hline \multicolumn{6}{|l|}{ Special } \\
\hline Mesh & rec, cyl, sph & rec, cyl & rec, cyl & rec, cyl, sph & rec,cyl \\
\hline Coincidence & Yes & No & Yes & Yes & Yes \\
\hline Residuals & Yes & No & Yes & Yes & Yes \\
\hline Activation & 2.5.D & $? ?$ & Yes & Yes & No \\
\hline Event logs & Yes & Yes & Yes & Yes & Yes \\
\hline Convergence Tests & 10 & Error & Error & Error & Error \\
\hline Viewer & $\begin{array}{l}\text { Built-in: } \\
\text { 1-D, 2-D Custom } \\
\text { X-Windows } \\
\text { External: } \\
\text { IDL } \\
\text { Tecplot } \\
\text { GNUplot } \\
\text { PAW }\end{array}$ & $\begin{array}{l}\text { Built-in: } \\
\text { No } \\
\text { External: } \\
\text { JAS } \\
\text { PI } \\
\text { Open Scientist }\end{array}$ & $\begin{array}{l}\text { Built-in: } \\
\text { None } \\
\text { External: } \\
\text { Custom (X11) } \\
\text { GNUplot } \\
\text { PAW } \\
\text { ROOT }\end{array}$ & $\begin{array}{l}\text { Built-in: } \\
\text { Custom } \\
\text { External: } \\
\text { PAW }\end{array}$ & $\begin{array}{l}\text { Built-in: } \\
\text { Angel } \\
\text { External: } \\
\text { Angel }\end{array}$ \\
\hline
\end{tabular}

Table 6. Overview of variance reduction capabilities for various all-particle transport codes.

\begin{tabular}{|c|c|c|c|c|c|}
\hline Variance Reduction & MCNPX & GEANT4 & FLUKA & MARS & PHITS \\
\hline $\begin{array}{l}\text { Population control } \\
\text { Region biasing } \\
\text { Weight cutoff } \\
\text { Weight window mesh } \\
\text { Energy biasing } \\
\end{array}$ & $\begin{array}{l}\text { Yes } \\
\text { Yes } \\
\text { Yes } \\
\text { Yes } \\
\end{array}$ & $\begin{array}{l}\text { Yes } \\
\text { Yes } \\
\text { Yes } \\
\text { No } \\
\end{array}$ & \begin{tabular}{|l} 
Yes \\
Yes \\
Yes \\
Yes \\
\end{tabular} & $\begin{array}{l}\text { Yes } \\
\text { Yes } \\
\text { Yes } \\
\text { Yes }\end{array}$ & $\begin{array}{l}\text { Yes } \\
\text { Yes } \\
\text { Yes } \\
\text { Yes } \\
\end{array}$ \\
\hline $\begin{array}{l}\text { Modified sampling } \\
\text { Source biasing } \\
\text { Implicit capture } \\
\text { Exp. transform } \\
\text { Production biasing } \\
\text { Angular bias } \\
\end{array}$ & $\begin{array}{l}\text { Yes } \\
\text { Yes } \\
\text { Yes } \\
\text { Yes } \\
\text { DXTRAN }\end{array}$ & $\begin{array}{l}\text { RDM } \\
\text { Yes } \\
\text { No } \\
\text { Yes } \\
? ?\end{array}$ & \begin{tabular}{|l} 
Yes \\
Yes \\
Yes \\
Yes \\
Yes \\
\end{tabular} & $\begin{array}{l}\text { Yes } \\
\text { Yes } \\
\text { Yes } \\
\text { Yes } \\
\text { Yes }\end{array}$ & $\begin{array}{l}\text { Yes } \\
\text { Yes } \\
\text { No } \\
\text { Yes } \\
\text { Yes } \\
\end{array}$ \\
\hline DXTRAN & Yes & No & No & No & No \\
\hline Viewer & 2-D contour & No & No & No & No \\
\hline
\end{tabular}




\section{Discussion of recent MCNPX features}

MCNPX [1] began in 1994 as a code-merger project of MCNP 4B [6] and LAHET 2.8 [7]. It was first released to the public in 1999 as version 2.1.5 [8]. In 2002, MCNPX was upgraded to MCNP 4C [9], converted to Fortran 90, enhanced with 12 new features, and released to the public as version 2.4.0 [10]. Since 2002, the MCNPX beta-test team has ballooned to over 1400 users at 300 institutions around the world; the code-development team has added dozens of new features with the release of version 2.5.0; code users have attended more than a dozen MCNPX international workshops; and MCNPX has become one of the most widely used radiation transport codes in the world.

MCNPX is a general-purpose radiation transport code that includes 3-D geometry, continuous-energy transport up to one $\mathrm{TeV}$, transport of 34 different particle types, a variety of source and tally options, interactive graphics, and support for a variety of sequential and multiprocessing computer platforms. Applications for the code are quite broad and constantly developing. Examples include the design and shielding of accelerators and reactors, medical therapies (neutron, photon, proton, etc.), dosimetry, imaging, space radiation, plasma transport, nuclear physics, detector design, and radiation effects on electronics.

The three most important aspects of MCNPX code development, given in their order of importance, are quality, value, and features. In regards to quality, the code development team is committed to zero defects through offering bug rewards ( $\$ 2$ for old bugs and $\$ 20$ for new bugs), placing a high priority on fixing reported bugs, developing an extensive test suite that approaches $100 \%$ code coverage (currently this suite exceeds 250 test problems), and following rigorous SQA procedures [11]. In regards to value, MCNPX code developers are dedicated to providing thorough documentation, organizing informative workshops, participating in benchmark analyses, and ensuring compatibility with a wide variety of compilers and computer hardware. In regards to features, the code development team works closely with international physicists and users to develop new capabilities that provide flexibility, generality, and reliability

Twenty-eight new features have been implemented in MCNPX 2.5.0 since the release of version 2.4.0 in August of 2002. Added to the twelve features introduced in version 2.4.0, a total of forty new features have been developed since the release of version 2.3.0 [12] in April of 2002. Furthermore, over 60 bugs were identified and corrected since the release of version 2.4.0 (75\% of these were $\$ 2$ awards for identifying MCNP bugs while the remaining $\$ 20$ awards were associated with new features). A subset of the new 2.5.0 features, those related to fast neutron transport, are discussed in the following three sections: User Enhancements, Physics Enhancements, and Infrastructure Enhancements.

\subsection{User Enhancements}

The fifteen user enhancements are further subdivided into four categories: sources, tallies, graphics, and general. 


\subsubsection{Sources}

Five new source features were introduced with version 2.5.0, three of which are relevant to fast neutron transport.

\subsubsection{Multiple source particles}

Multiple types of source particles may now be specified on the SDEF card. This is accomplished by specifying either an independent or dependent distribution for the PAR keyword. Note that a particle type may be listed more than once on an SI or DS card. This enables the user to specify a different spatial, energy, or angular distribution even for the same particle type. Tallies and summary tables are normalized by dividing the total source weight by the number of source histories.

\subsubsection{Sources on cylindrical surfaces}

Cylindrical surface sources may now be specified on the SDEF card. Furthermore, particle directions relative to the cylindrical surface normal may be specified. The cylindrical surface can be, but does not have to be, a cell-bounding problem surface. Likewise, a spherical surface source no longer has to be on a cell-bounding problem surface. In MCNP and earlier MCNPX versions, the only way to specify a cylindrical surface source was to have a degenerate cylindrical volume source ( $\mathrm{RAD}=$ constant) that is not also a problem surface. In such cases, the particle direction had to be isotropic from each sampled point. An example of a cylindrical source that lies on a problem surface with the default cosine angular distribution follows:

\section{SDEF POS=0 00 RAD=1 EXT=d1 AXS=1 00 SUR=5}

To specify a cylindrical surface source that does not lie on a problem surface simply omit the SUR keyword. The default cosine distribution, which is relative to the cylindrical surface normal, may be altered using the DIR keyword.

\subsubsection{Extension of the TR keyword}

The TR (transformation) keyword on the SDEF card has been enhanced to remove incompatibilities with other keywords (e.g., CEL) and to allow for the use of dependent distributions. The TR keyword must be sampled before sampling the particle position, therefore it cannot be a dependent distribution of any position keywords (e.g., X, Y, Z, or POS). Due to previous functionality of the TR and CCC keywords, if the TR keyword is defined by an explicit value or an independent distribution then CCC rejection is performed before the specified transformation is applied. Therefore a single CCC rejection cell can be used to shape a source specified at multiple locations.

\subsubsection{Tallies}

Four new tally features were introduced with version 2.5.0, three of which are relevant to fast neutron transport.

\subsubsection{Anticoincidence pulse-height tally option}

A new FT PHL option is available for pulse-height tallies. This option allows F8 tallies to be based on energy deposition (or light production) in one or two regions as specified by one 
or more F6 tallies. Furthermore, energy deposition from one or more particle types can be combined, converted to light output, and posted in the proper F8 tally bin. Using the two-region format, an entire coincidence/anti-coincidence pulse-height matrix can be produced. The format of the FT PHL option is:

FT8 PHL N $\mathbf{T}_{\mathrm{A} 1} \mathbf{B}_{\mathrm{A} 1}\left[\mathbf{T}_{\mathrm{A} 2} \mathbf{B}_{\mathrm{A} 2} \ldots\right] \mathbf{M}\left[\mathbf{T}_{\mathrm{B} 1} \mathbf{B}_{\mathrm{B} 1} \mathbf{T}_{\mathrm{B} 2} \mathbf{B}_{\mathrm{B} 2} \ldots\right]$

where $\mathrm{N}=$ number of $\mathrm{F} 6$ tallies for the first detector region, $\mathrm{T}_{\mathrm{Ai}} \mathrm{B}_{\mathrm{Ai}}=$ pairings of tally number and F-bin number for the N F6 tallies of the first detector region, $\mathrm{M}=$ number of $\mathrm{F} 6$ tallies for the second detector region, and $\mathrm{T}_{\mathrm{Bi}} \mathrm{B}_{\mathrm{Bi}}=$ pairings of tally number and F-bin number for the M F6 tallies of the second detector region. When $\mathrm{M}$ is zero, indicating a one-region tally, energy channels may be specified on an E8 card. When M is nonzero, indicating a two-region tally, an FU card must be used to enter the energy channels for the $2^{\text {nd }}$ region.

\subsubsection{Coincidence capture pulse-height tally option}

The new pulse-height FT CAP option scores the number of captures in specified combinations of nuclides at the end of each history. It is particularly useful for neutron coincidence detectors [13]. In addition, capture events may be written to the PTRAC output file. The format of the CAP option is:

FT8 CAP [-N] [-M] $\mathbf{I}_{\mathbf{1}}\left[\begin{array}{lll}\mathbf{I}_{2} & \ldots\end{array}\right]$

where $\mathrm{N}=$ optional maximum number of captures (default=21), $\mathrm{M}=$ optional maximum number of moments (default=12), and $\mathrm{I}_{\mathrm{i}}=$ capture nuclides in ZAID format (e.g., 3006, 5010, etc.). Use of the CAP option automatically sets analog capture, enhanced fission multiplicity (see section 2.2.2.1), and exits with an error message if variance reduction is used. The capture multiplicities and moments are presented in Print Table 118.

\subsubsection{Residual nuclei pulse-height tally option}

Residual nuclei from nuclear interactions in the model physics energy range may be tallied with the pulse-height FT RES option. The format of this option is:

\section{FT8 RES $\left[Z_{1} \mathbf{Z}_{2}\right]$}

where $Z_{1}$ (default=1) and $Z_{2}$ (default=99) are optional lower and upper limits of $Z$ values to include in the tally. The residuals are recorded at each interaction in the model physics, and over 2000 user bins are created with the default values of $Z_{1}$ and $Z_{2}$, one for each possible residual nucleus ZAID. This option is particularly useful when the $8^{\text {th }}$ entry on the LCA card is set to -2 , in which case the distribution of residual nuclides is that produced by the first source collision.

\subsubsection{Graphics}

Three new graphics capabilities were introduced with version 2.5.0.

\subsubsection{Lattice index labeling}

Lattice indices may now be used as plot labels in geometry plots. If the active level of a geometry plot (adjusted with the LEVEL button) does not include a lattice cell, then the indices of any lattice at a higher level will be displayed. To get the lattice index labels, choose "ijk" as the edit quantity and then click on the $2^{\text {nd }}$ entry following LABEL. 


\subsubsection{WWG superimposed mesh plots}

MCNPX can now plot the weight-window generator (WWG) superimposed mesh specified on the MESH card in an input file. Previous versions could only plot the mesh read from the WWINP file. The CellLine button in the interactive plotter can be used to toggle between the following options: (1) CellLine = plot geometric cells outlined in black; (2) WW $\mathrm{MESH}=$ plot the weight-window superimposed mesh from the WWINP file; (3) WW+Cell = plot superimposed WWINP mesh and cells outlined in black; (4) WWG MESH = plot MESH card WWG mesh; (5) WWG+Cell = plot MESH card WWG mesh and cells outlined in black; and (6) No Lines $=$ omit cell lines.

\subsubsection{Color contour tally plots}

For the first time, tally, lattice, and mesh data may now be plotted as 2-D color contours from either MCTAL or RUNTPE files. For example, a rectangular mesh tally with bins specified on CORA, CORB, and CORC cards can be plotted with the MCNPX Z option, as illustrated in Fig. 1. The FREE and CONTOUR plot commands have been extended to support this feature:

\section{FREE X[Y] [NxM]}

CONTOUR CMIN CMAX CSTEP [\%] [ALL|NOALL] [line|noline] [color|nocolor]

Variables $\mathrm{X}$ and $\mathrm{Y}$ are tally bin indices (fdusmcet) or lattice/mesh indices (ijk). Specifying a single variable after the FREE command produces a 1-D plot. Specifying two variables produces a 2-D contour plot. The NxM keyword is required only when a lattice description omits use of the extended FILL card, and it specifies the number of bins associated with the $\mathrm{X}$ and $\mathrm{Y}$ lattice indices. The ALL keyword specifies that the minimum and maximum contour range should be taken from all of the tally bins (default is to use the bins only in the current plot, or NOALL). 


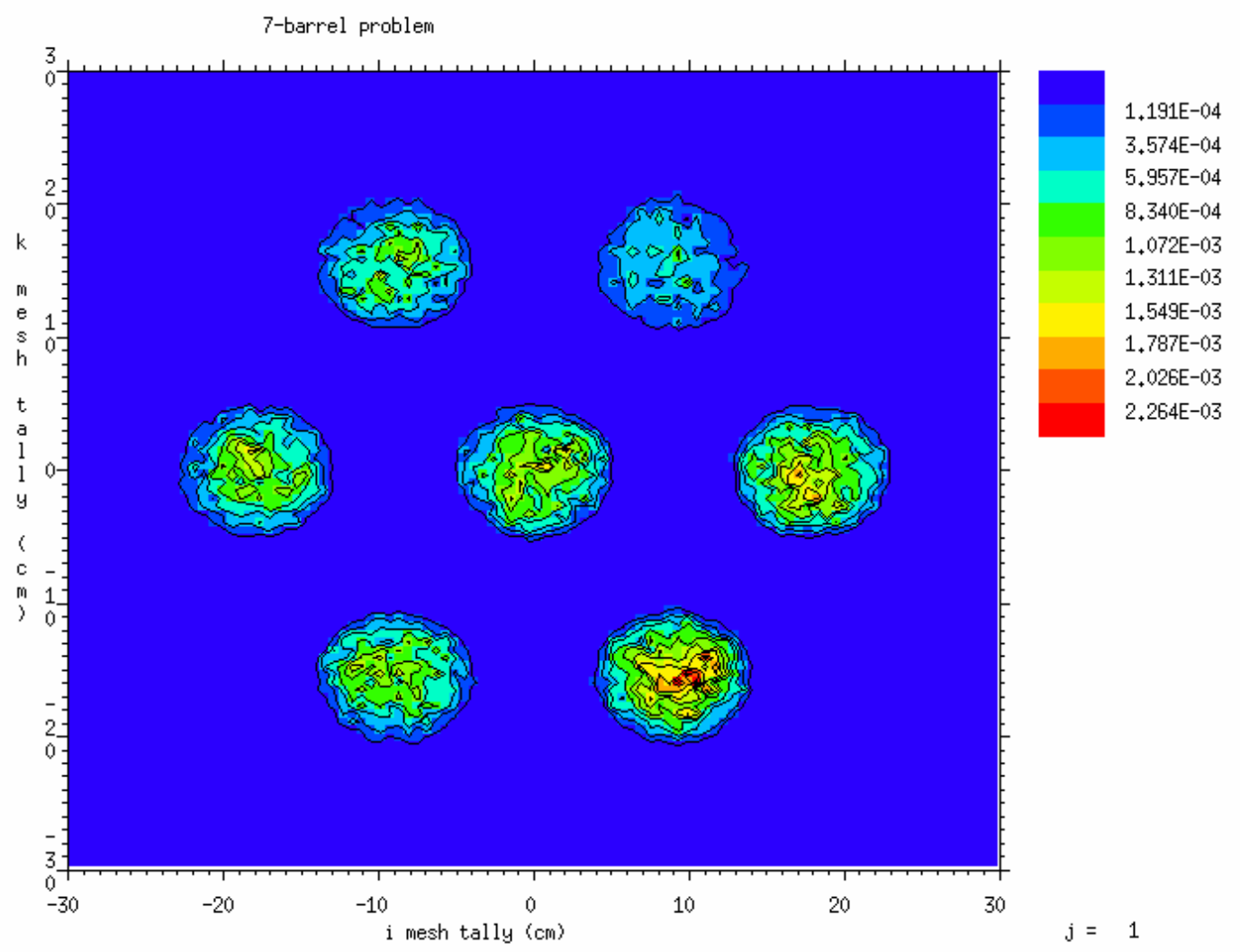

Figure 1. A mesh tally plot of fission source points within seven cans containing uranium.

\subsubsection{General}

Three other miscellaneous capabilities were introduced with version 2.5.0: READ card, HISTP file-size control, and DXTRAN/Detector underflow control.

The READ card is a new input card that allows for reading parts of an input deck from another file and for encryption of input read from another file. The READ card may appear anywhere after the title card of an MCNPX input file but not in the middle of a card continuation. The format of the READ card is:

\section{READ FILE=filename [ECHO | NOECHO] [DECODE | ENCODE=password]}

This card causes input from the file filename to be inserted after the READ command in the MCNPX input deck. Unlike most MCNPX input cards, there may be as many READ cards and auxiliary input files as desired. The ECHO (default) or NOECHO keyword will either include or omit printing of the additional input lines to the output file. The DECODE keyword and password may be included to decrypt the input lines from an encrypted file. A simple encryption scheme is provided in MCNPX, and it can be used to protect proprietary designs of devices.

The HISTP card controls the writing of model interaction information to an external file for analysis by the HTAPE3X program. An option has been added to this card to allow the user to control the size of sequenced HISTP files. 
DXTRAN and point-detector contributions are based on the next-event estimator which includes an exponential term of $\mathrm{e}^{-\lambda}$, where $\lambda$ is the sum of the total macroscopic cross section times the track length for each material region crossed between the collision and detector or DXTRAN sphere. In previous versions of MCNPX, if $\lambda>80$, then this exponential term is assumed to be zero, and the score is terminated as "underflow in transmission." While in most cases these contributions are insignificant to the final answer, in some cases we have found that the underflow contribution is significant and needed (e.g., when DXTRAN spheres or point detectors are used to get tally contributions for generating weight windows). It is now possible to specify the underflow limit with the $6^{\text {th }}$ entry on the DBCN card.

\subsection{Physics Enhancements}

The nine physics enhancements are further subdivided into two categories: model and neutron.

\subsubsection{Model}

Four new model physics enhancements were introduced with version 2.5.0.

\subsubsection{Mix-and-match}

The MCNPX "mix-and-match" capability enables mixing and matching of physics models and data tables. It is now possible to specify some nuclides with models and other nuclides with data tables (isotope "mixing"). It is also possible to use data tables up to their maximum energy value and then use models above that energy, even when the maximum table energy differs from nuclide to nuclide (energy "matching"). The energy-matching feature is now the default and is controlled by the $5^{\text {th }}$ entry on the PHYS:N card and the $3^{\text {rd }}$ entry on the PHYS:H card. The mixing feature is accomplished with the new MX card, which enables nuclide substitution by particle type (it is an extension of and replacement for the MPN card). The format of this card is:

MXn: $<$ pl $>\operatorname{zaid}_{1}$ zaid $_{2} \ldots$

where $\mathrm{n}=$ material number of a related $\mathrm{Mn}$ card that must precede the MXn card, $<$ pl $>=$ particle type $(\mathrm{N}, \mathrm{P}$, or $\mathrm{H})$, and zaid $_{i}=$ ZAID of replacement nuclide for the $\mathrm{i}^{\text {th }}$ nuclide on the Mn card. Use of this card for photons indicates photonuclear replacements, not photoatomic. No substitutions are allowed for photoatomic and electron data because those data sets are complete. The MXn:P card is an exact replacement of the MPNn card, and photonuclear nuclide substitutions of $z^{a i d}{ }_{i}=0$ is allowed to omit the use of photonuclear data for a specific nuclide. An entry of $z_{a i d}=$ model is allowed on the MXn:N and MXn:H cards to specify the use of a model instead of tabular data. Consider the following example:

\begin{tabular}{|c|c|c|c|}
\hline $\mathrm{m} 1 \quad 10021$ & 1003.61 & 60121 & $200401 \mathrm{NLIB}=24 \mathrm{c}$ \\
\hline mx1:n j & model & 6000 & 20000 \\
\hline mx1:h model & 1001 & $\mathbf{j}$ & $\mathbf{j}$ \\
\hline mx1:p 6012 & $\mathbf{0}$ & $\mathbf{j}$ & $\mathbf{j}$ \\
\hline
\end{tabular}

In this case, neutron interactions are treated by a model for ${ }^{3} \mathrm{H}$, a natural carbon library for ${ }^{12} \mathrm{C}$, and a natural calcium library for ${ }^{40} \mathrm{Ca}$. Proton interactions are treated by a model for ${ }^{2} \mathrm{H}$ and a ${ }^{1} \mathrm{H}$ library for ${ }^{3} \mathrm{H}$. Photonuclear interactions are treated by a ${ }^{12} \mathrm{C}$ library for ${ }^{2} \mathrm{H}$ and no interactions 
for ${ }^{3} \mathrm{H}$. The " $\mathrm{j}$ " entries on the MX cards default to libraries, when available, and models otherwise. A new table, Print Table 101, is provided in the output file to summarize the energy matching.

Fig. 2 shows an example of the mix-and-match capability. For this simulation, $100 \mathrm{MeV}$ neutrons are incident on a BGO crystal $(3.932 \mathrm{~cm}$ radius by $8.433 \mathrm{~cm}$ length). The crystal contains $21 \% \mathrm{Bi}, 16 \% \mathrm{Ge}$, and $63 \% \mathrm{O}$, and Ge libraries were not available. The solid line represents flux in the crystal with the full mix-and-match capability, which uses all libraries up to their energy limits, physics models above those limits, and models for Ge. The dashed-line calculation uses the old method of substituting As for the missing Ge library, using the libraries up to $20 \mathrm{MeV}$, and physics models above. The dotted line uses Bi and O libraries up to their limits of $150 \mathrm{MeV}$, the As library up to its limit of $20 \mathrm{MeV}$ and then the $20 \mathrm{MeV}$ data are used from $20-150 \mathrm{MeV}$, and above $150 \mathrm{MeV}$ physics models are used for all three nuclides. This last option is least desirable but was often used in past code versions to take advantage of the $150-\mathrm{MeV}$ libraries, even though many data libraries only go to $20 \mathrm{MeV}$.

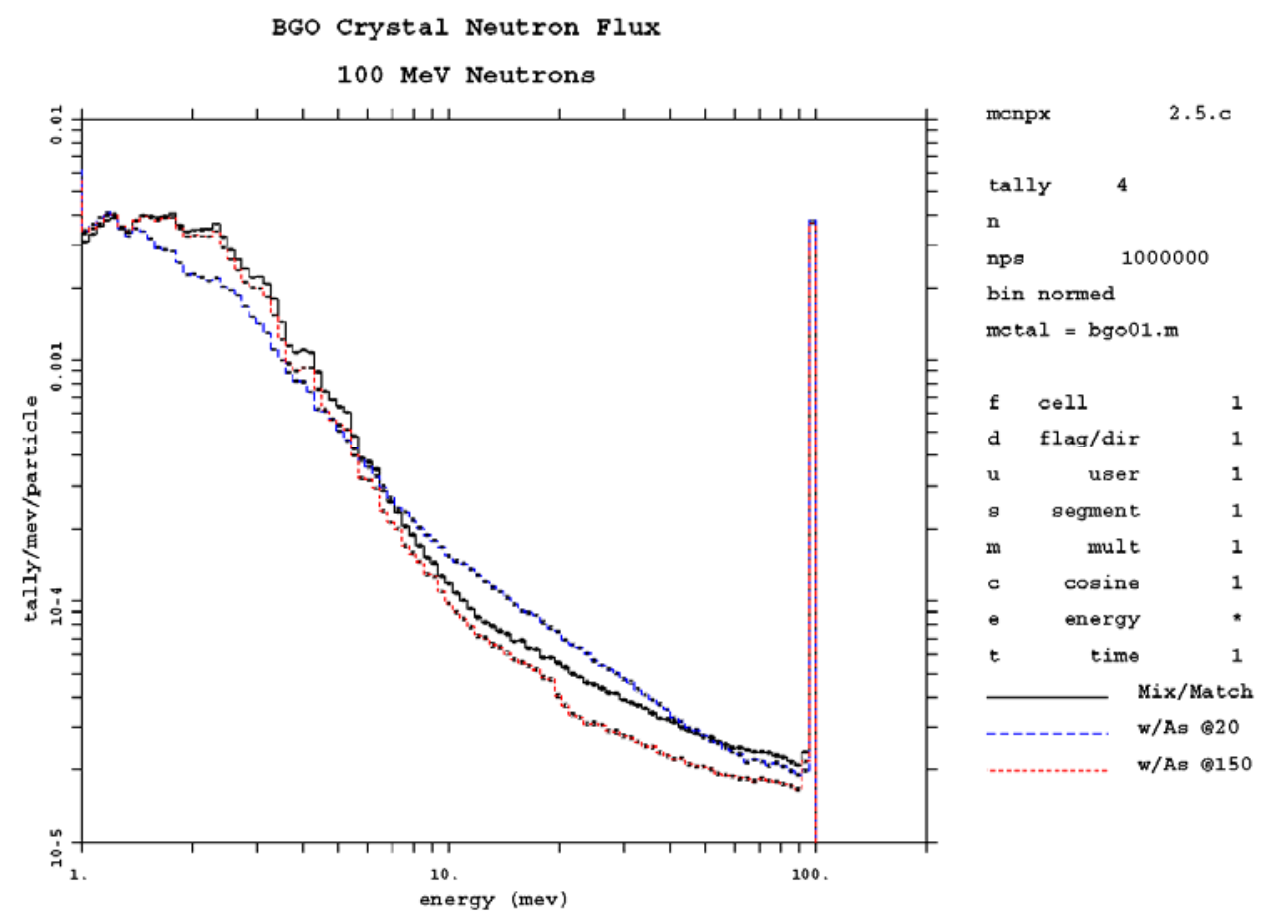

Figure 2. Comparison of different germanium library and model options.

\subsubsection{CEM physics model upgrade}

The MCNPX CEM physics model has been upgraded from CEM95 to CEM2K [14]. It is still controlled by the $9^{\text {th }}$ entry on the LCA card (ICEM). This model assumes that reactions occur in three stages. The first stage is the intra-nuclear cascade, in which primary particles can have one or more interactions, thus producing secondary particles several times before absorption by or escape from the nucleus. The excited residual nucleus that remains after the cascade determines the particle-hole configuration, which is the starting point for the pre- 
equilibrium stage of the reaction. The subsequent relaxation of the nuclear excitation is treated in terms of an improved modified exciton model of pre-equilibrium decay, followed by the equilibrium evaporative final stage of the reaction, which is competing with the fission and Fermi-breakup channels.

CEM2K incorporates new approximations for the elementary cross sections used in the cascade, using more precise values for nuclear masses and pairing energies, corrected systematics for the level-density parameters, and several other refinements. Improved algorithms decrease the computing time by up to a factor of six for heavy targets. Other improvements were motivated by new measured data on isotope production from Gesellschaft für Schwerionenforschung (GSI) experiments. Compared with earlier versions, CEM2K has a longer cascade state, less pre-equilibrium emission, and less evaporation from more highly excited compound nuclei. CEM2K also has better models of neutron, radionuclide, and gas production in accelerator-transmutation-of-waste spallation targets.

\subsubsection{INCL4/ABLA physics model addition}

The IntraNuclear Cascade, Liege (INCL4) [15] and ABLA [16] fission-evaporation models are now available in MCNPX. The INCL model is invoked with the $9^{\text {th }}$ entry on the LCA card (ICEM=2), and the ABLA fission model is invoked with the $7^{\text {th }}$ entry on the LEA card (IEVAP=2). The LCC card controls various parameters used by the INCL model. The INCL4 model is based largely on the work of colleagues at the University of Liege in Liege, Belgium. This model generally is coupled with the ABLA fission-evaporation model that was developed principally at GSI in Darmstadt, Germany. The integration of these models into MCNPX has been done principally by Jean-Christophe David at Commissariat à l'Energie Atomique-Saclay, France. INCL4 and ABLA are intended for use in the $200 \mathrm{MeV}$ to $2 \mathrm{GeV}$ energy range. In its present implementation, INCL is much slower than the Bertini and CEM2K models.

With the addition of INCL4 and ABLA, there are now seven INC/fission model combinations available: Bertini/Dresner, CEM2K, ISABEL/Dresner, Bertini/ABLA, ISABEL/ABLA, INCL4/Dresner, and INCL4/ ABLA. Fig. 3 gives an example of neutronproduction results for several of these combinations.

\subsubsection{Generation of secondary-particle production cross sections}

A new LCA option was develop to allow for tallying secondary-particle production cross sections in the model energy regime. When the $8^{\text {th }}$ entry on the LCA card (NOACT) is set to -2 , source particles undergo a single interaction, at the point of origin, and all subsequent particles escape (i.e., transport through a void). Tallying of the differential cross sections can be done with standard F1 surface tallies (see Fig. 3 for an example). 


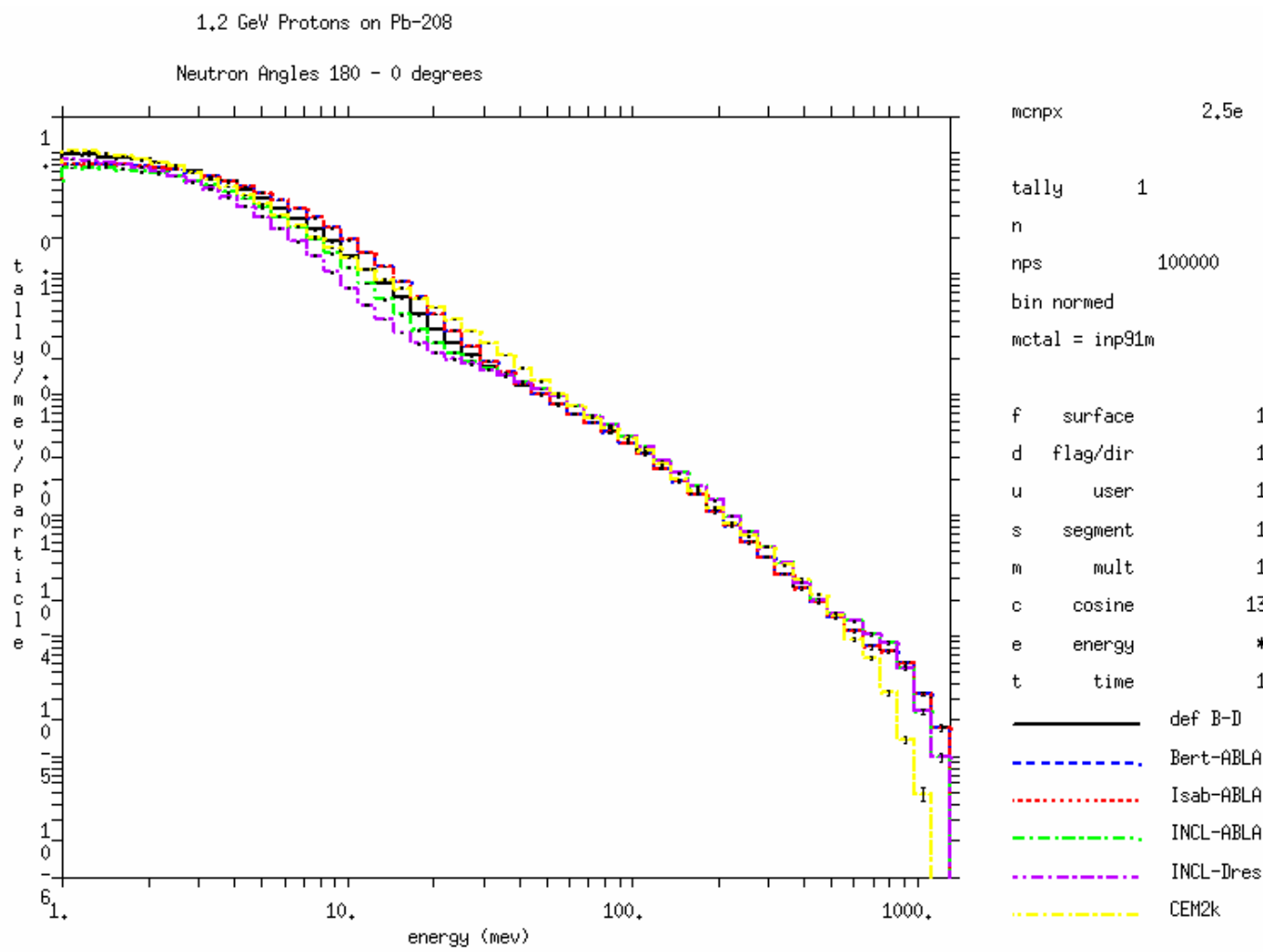

Figure 3. Double-differential cross sections of neutron production from $1.2 \mathrm{GeV}$ protons on ${ }^{208} \mathrm{~Pb}$ using six MCNPX model combinations.

\subsubsection{Neutron}

Two new neutron physics enhancements were introduced with version 2.5.0, one of which is related to fast neutron transport.

\subsubsection{Fission multiplicity}

Fission multiplicity is the number of neutrons produced by a fission event. The nuclear data tables provide the average number of fission neutrons, $v$, per fission. The default MCNPX treatment is the MCNP treatment: the number of neutrons per fission is the integer above or below $v$. If $v=2.7$, then the number of neutrons will be two $30 \%$ of the time and three $70 \%$ of the time. However a user may now invoke a more precise fission multiplicity treatment with the $6^{\text {th }}$ entry on the PHYS:N card (FISM). When FISM is positive, then $v$ is sampled from a Gaussian with FWHM $=$ FISM. If FISM $<1$, then $v$ is sampled from a Gaussian with FWHM $=$ 1.079, unless the fissioning nuclide is one of the following: ${ }^{232} \mathrm{Th},{ }^{232} \mathrm{U},{ }^{233} \mathrm{U},{ }^{234} \mathrm{U},{ }^{235} \mathrm{U},{ }^{236} \mathrm{U}$, ${ }^{238} \mathrm{U},{ }^{237} \mathrm{~Np},{ }^{238} \mathrm{Pu},{ }^{239} \mathrm{Pu},{ }^{240} \mathrm{Pu},{ }^{241} \mathrm{Pu},{ }^{242} \mathrm{Pu},{ }^{241} \mathrm{Am},{ }^{242} \mathrm{Cm},{ }^{244} \mathrm{Cm},{ }^{249} \mathrm{Bk}$, and ${ }^{252} \mathrm{Cf}$. For these nuclides, the spontaneous fission multiplicity data of Ensslin [17] are used. The energies are sampled from a Watt spectrum with appropriate spontaneous fission parameters for the selected nuclide. 


\subsection{Infrastructure Enhancements}

The three infrastructure enhancements include 64-bit integers, support for new compilers, and MPI support.

\subsubsection{4-bit integers}

MCNPX has been restructured to enable 64-bit integers. Four-byte integers limit the number of histories that can be run to about 2 billion. They also limit the number of cross sections and tallies in a problem since these arrays are accessed with integer offset variables. With 64-bit-integers, up to $1 \mathrm{e} 18$ histories can be run, and the limit on cross-section and tally storage is essentially removed. The print field for the number of histories has been increased to 12 digits to accommodate the long runs now possible with parallel processing. The default build of MCNPX still invokes 4-byte integers, but this may change in the near future. To invoke an 8byte integer build, use the following configure options:

--with-NOCHEAP --with-FFLAGS=-i8

Note that the "-i8" compiler flag is different on some systems (consult the MCNPX build instructions for further details).

\subsubsection{Support for new compilers}

MCNPX now runs on a wider variety of platforms and operating systems by using more standard F90 constructs and implementing extensive code and autoconfiguration changes. In particular, it runs on the Mac G5 OS X system using either the IBM or NAG compiler. The NAG compiler passes the MCNPX SGI test suite on the Mac with "-O1" optimization. The IBM compiler passes with "-O2" optimization and is about $17 \%$ faster. Furthermore, the Intel compiler is now supported on both Linux and Windows platforms. In fact, the default build for Windows has been switched to the Intel compiler (CVF will remain as an option for a couple of years). A timing study was performed using the MCNP5 42-problem test suite and a $1 \mathrm{GHz}$ Pentium 4 Windows PC. The test suite was modified to increase the number of particle histories of each input by a factor of ten to ensure accuracy of the timing results. The MCNPX Intel executable ran the test suite an average of $24 \%$ faster than the CVF executable, and it outperformed MCNP5 (version 1.14) by an average of $10 \%$.

\subsubsection{MPI support}

The MCNPX multi-processing capability was enhanced to support the MPI parallel communication standard. MPI message buffers are dynamically adjusted to accommodate messages up to 400 Mbytes in length. A user can adjust this by modifying one line in the source code and recompiling. Details for building an MPI version are provided in the installation instructions, and installation notes for some systems are provided on the MCNPX web site. On most systems it is recommended that you first download and install the public version of MPICH [18]. The new MCNPX configure options are:

\footnotetext{
--with-MPILIB[="/path/to/MPI/libraries -Impich"] --with-MPICH --with-FFLAGS=“-I/path/to/MPI/include/files”
} 


\section{Conclusions}

Twenty-eight new features have been implemented in MCNPX version 2.5.0. This accounts for the largest number of new features ever implemented in a new version of either MCNP or MCNPX. These features provide a significant benefit to radiation transport users and have vaulted MCNPX into one of the most widely used Monte Carlo codes in the world. Development for version 2.6.0 is well underway with plans to include such features as the following: enhanced eigenfuction convergence, delayed neutron and gamma models, heavy-ion transport, CEM03, transmutation, and tracking through magnetic fields.

\section{References}

[1] D. B. Pelowitz, ed., MCNPX User's Manual, Version 2.5.0, Los Alamos National Laboratory report, LA-CP-05-0369 (April 2005).

[2] S. Agostinelli et al., GEANT4 - A Simulation Toolkit, Nucl. Inst. and Methods in Physics Research A, 506, pp.250-303 (2003).

[3] A. Fasso, A. Ferrari, et al., The Physics Models of FLUKA: Status and Recent Developments, Proceedings of Computing in High Energy and Nuclear Physics 2003 Conference, La Jolla, CA, USA (March 2003).

[4] N. V. Mokhov and C. C. James, The MARS Code System User's Guide, Version 15 (2006), Fermi National Accelerator Laboratory report (February 2006).

[5] H. Iwase, K. Niita, and T. Nakamura, Development of General-Purpose Particle and Heavy Ion Transport Monte Carlo Code, J. Nucl. Sci. Technol., 39, p.1142 (2002).

[6] J. F. Briesmeister, ed., MCNP-A General Monte Carlo N-Particle Transport Code, Version 4B, Los Alamos National Laboratory report, LA-12625-M (March 1997).

[7] R. E. Prael and D. G. Madland, LAHET Code System Modifications for LAHET 2.8, Los Alamos National Laboratory report, LA-UR-95-3605 (September 1995).

[8] L. S. Waters, ed., MCNPX User's Manual Version 2.1.5, Los Alamos National Laboratory report, LA-UR-99-1995 (September 1999).

[9] J. F. Briesmeister, ed., MCNP-A General Monte Carlo N-Particle Transport Code, Version 4C, Los Alamos National Laboratory report, LA-13709-M (April 2000).

[10] L. S. Waters, ed., MCNPX User's Manual Version 2.4.0, Los Alamos National Laboratory report, LA-CP-02-408 (September 2002).

[11] H. M. Abhold and J. S. Hendricks, MCNP Software Quality Assurance Plan, Los Alamos National Laboratory report, LA-13138 (April 1996).

[12] L. S. Waters, ed., MCNPX User's Manual Version 2.3.0, Los Alamos National Laboratory report, LA-UR-02-2607 (April 2002).

[13] J. S. Hendricks et al., Neutron Multiplicity Counting for Nuclear Safeguards with MCNPX, Transactions of the American Nuclear Society, San Diego, CA, June 1-5 (2003).

[14] S. G. Mashnik and A. J. Sierk, Recent Developments of the Cascade-Exciton Model of Nuclear Reactions, Los Alamos National Laboratory report, LA-UR-01-5390 (October 2001).

[15] A. Boudard et al., Intranuclear Cascade Model for a Comprehensive Description of Spallation Reaction Data, Physical Review C, 66, 044615 (October 2002).

[16] A. R. Junghans et al., Projectile-Fragment Yields as a Probe for the Collective Enhancement in the Nuclear Level Density," Nuclear Physics A, 629, pp.635-655 (1998).

[17] N. Ensslin et al., Application Guide to Neutron Multiplicity Counting, Los Alamos National Laboratory report, LA-13422-M (November 1998).

[18] W. Gropp et al., MPICH2 User's Guide, Version 1.0.3, Argonne National Laboratory report (November 2005). 